\title{
Predicting outcomes in esophageal cancer: No such thing as a crystal ball
}

\author{
Matthew J. Bott, MD
}

\author{
From the Thoracic Service, Department of Surgery, Memorial Sloan Kettering Cancer Center, New York, NY. \\ Disclosures: Author has nothing to disclose with regard to commercial support. \\ Received for publication March 26, 2018; accepted for publication March 28, 2018; available ahead of print May \\ $10,2018$. \\ Address for reprints: Matthew J. Bott, MD, Thoracic Service, Department of Surgery, Memorial Sloan Kettering \\ Cancer Center, 1275 York Ave, New York, NY 10065 (E-mail: bottm@mskcc.org). \\ J Thorac Cardiovasc Surg 2018;156:845-6 \\ $0022-5223 / \$ 36.00$ \\ Copyright $(C) 2018$ by The American Association for Thoracic Surgery \\ https://doi.org/10.1016/j.jtcvs.2018.03.133
}

In this issue of the Journal, Gupta and colleagues ${ }^{1}$ present a systematic review of the currently published tools for predicting patient survival after treatment for esophageal cancer. Their painstaking analysis uses a recently published checklist from the American Joint Committee on Cancer, which contains 13 inclusion criteria and 3 exclusion criteria that clinicians can use to evaluate the quality of a particular prognostic model and determine its relevance to their clinical practice. ${ }^{2}$ The work of Gupta and colleagues ${ }^{1}$ is timely, because the eighth edition of the TNM staging manual advocates the use of such tools as companions to the existing TNM staging system when estimating mortality risk in patients with cancer. ${ }^{3}$

Gupta and colleagues ${ }^{1}$ determine that none of the 17 prognostication tools in the literature meet all the specified American Joint Committee on Cancer quality measures. This is unfortunate yet perhaps unsurprising news for those of us who treat patients with this challenging disease. A cursory review of the included studies underscores the degree of the deficiency identified by Gupta and colleagues. ${ }^{1}$ Of the 17 studies, 10 focus specifically on patients with squamous cell carcinoma, and none were prospectively designed for the purpose of creating a clinical prediction model. Because most of these studies comprised patients treated before 2000, only 4 included patients treated with trimodality therapy. The survival data contained in these models are thus perhaps only vaguely applicable to most patients in Western countries treated in the modern era.

The study has several strengths, including its rigorous analysis and its use of currently accepted quality measures. It also brings much-needed attention to the lack of validated survival algorithms for patients with esophageal cancer. Although highlighting this deficit is worthwhile, the study leaves the clinician wanting a usable tool that is currently applicable to modern practice. It should also be noted that, despite referencing "prediction tools," Gupta and colleagues $^{1}$ focus on algorithms for prognostication of survival, not necessarily response to treatment. They do make the point that, in the field of prediction tool interchangeably.

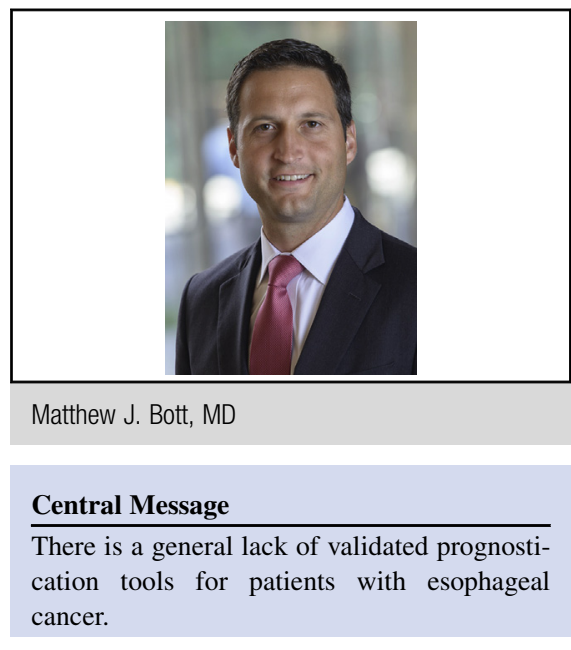

See Article page 847.

development, contrary to the field of oncology, the terms "prognostic" and "predictive" are often used

The review does identify a single study, by Gabriel and coworkers, ${ }^{4}$ that comes close to achieving all the American Joint Committee on Cancer quality measures; however, it falls short in that it does not provide a particular point in time from which prognostication began and it fails to include the number of deaths in the exploratory cohort. The study itself involves data on almost 9000 patients with esophageal cancer obtained from the National Cancer Database. It is important to note that the goal of this study was to identify predictors of benefit from neoadjuvant chemoradiation; it therefore includes only preoperative data (Charlson-Deyo score, tumor grade, clinical T and $\mathrm{N}$ status, and the use of neoadjuvant chemoradiotherapy) in its prediction algorithm. In addition, the model was internally validated with a subset of patients from the National Cancer Database, but it has not yet been externally validated.

As the study by Gupta and colleagues ${ }^{1}$ clearly demonstrates, much work remains to develop validated survival prediction models that can be used in concert with traditional TNM staging for patients with esophageal cancer. Perhaps the first step would be external validation of the current published algorithms with more granular, multi-institutional cohorts. Similarly, the addition of postoperative pathologic data to an algorithm such as the one developed by Gabriel and coworkers ${ }^{4}$ might provide 
further insight. In the era of personalized medicine, one must also wonder whether genomic data can provide novel prognostic information that might complement the currently available clinical and histopathologic parameters. Although our understanding of the genetic underpinnings of esophageal cancer has advanced considerably during the past several years, it remains well behind that of other malignancies, such as lung adenocarcinoma. Additional studies designed to evaluate genetic determinants of survival and identify aberrations that are predictive of treatment response would be of great benefit.

Gupta and colleagues ${ }^{1}$ are to be congratulated on this important contribution to the literature. Hopefully their work will call attention to the deficiency of the current prognostic models in esophageal cancer and will stimulate others to create and hone additional tools to enhance survival estimates, select patients for treatment, and better inform recruitment for clinical trials.

\section{References}

1. Gupta V, Coburn N, Kidane B, Hess KR, Compton C, Ringash J, et al. Survival prediction tools for esophageal and gastroesophageal junction cancer: a systematic review. J Thorac Cardiovasc Surg. 2018;156:847-56.

2. Kattan MW, Hess KR, Amin MB, Lu Y, Moons KG, Gershenwald JE, et al; members of the AJCC Precision Medicine Core. American Joint Committee on Cancer acceptance criteria for inclusion of risk models for individualized prognosis in the practice of precision medicine. CA Cancer J Clin. 2016;66:370-4.

3. Amin MB, Edge SB, Greene FL, Byrd DR, Brookland RK, Washington MK, et al., eds. AJCC Cancer Staging Manual. 8th ed. New York: Springer; 2017.

4. Gabriel E, Attwood K, Shah R, Nurkin S, Hochwald S, Kukar M. Novel calculator to estimate overall survival benefit from neoadjuvant chemoradiation in patients with esophageal adenocarcinoma. J Am Coll Surg. 2017; 224:884-94.e1. 